\title{
O PROCESSO CIVIL DE 2015 COMO QUALIFICADOR DA LINGUAGEM, SOCIALIZAÇÃO E INTERAÇÃO HUMANA
}

\author{
Claudio Cesar Carvalho* \\ Luiz Fernando Bellinetti**
}

\section{RESUMO:}

O presente trabalho tem por escopo analisar o Código de Processo Civil de 2015 e seus respectivos princípios norteadores conforme os pontos de intersecção para com a Filosofia do Direito, basicamente na instrumentalidade do processo como um viés qualificador da linguagem, socialização e interação humana, com vistas à formação não apenas de uma tutela jurisdicional justa, mas que correspondam as expectativas sociais e incrementem o acesso à justiça. Partindo-se de uma pesquisa bibliográfica, pelo método dedutivo, utilizou-se como parâmetros e de forma análoga as lições de Cândido Rangel Dinamarco, Clodomiro José Bannwart Junior, Lawrence Kohlberg e Jürgen Habermas.

Palavras-chave: Processo civil; princípios universais; linguagem; interação humana; acesso à justiça.

\section{THE 2015 CIVIL PROCESS AS A QUALIFIER OF HUMAN LANGUAGE, SOCIALIZATION AND INTERACTION}

\section{ABSTRACT:}

This paper aims to analyze the 2015 Civil Procedure Code and its guiding principles according to the points of intersection with the Philosophy of Law, basically in the instrumentality of the process as a qualifying bias of language, socialization and human interaction, with a view to the formation not only of fair judicial protection, but of meeting social expectations and increasing access to justice. Starting from a bibliographical research, by the deductive method, we used as parameters and analogously the lessons of Cândido Rangel Danish, Clodomiro José Bannwart Junior, Lawrence Kohlberg and Jürgen Habermas.

Keywords: Civil lawsuit; universal principles; language; human interaction; access to justice.

\section{INTRODUÇÃO}

A doutrina começa a discorrer sobre a alteração da base principiológica do Processo Civil, a partir do CPC-2015 [Lei n. ${ }^{\circ}$ 13.105/2015]. A ideia de cooperação e boa-fé ganharam alento diante das políticas estatais de consensualismo e, inclusive, desmassificação de ações judiciais.

\footnotetext{
"Mestrando em Direito Negocial (UEL). Detém Especializações e Licenciatura Plena. Advogado, Professor e Palestrante, nas linhas de Processo Civil e Acesso à Justiça. E-mail: contato@ claudiocesarcarvalho.com.br.

*** Professor Associado da UEL. Doutor em Direito (PUC-SP). Foi Procurador de Justiça no Estado do Paraná. Email: luizbel@uol.com.br.
} 
O rompimento para com a base principiológica do CPC-1973 [Lei n. ${ }^{\text {o }}$ 5.869/1973] não apenas traz a tona os estudos formais do Direito, mas uma chamativa maior: para que se discorra sobre o atual contexto hermenêutico do atual ordenamento processual civil brasileiro.

Para que isto ocorra, e em se tratando de diretrizes principiológicas, a Filosofia parece a melhor aliada na busca respostas que os processualistas ainda não conseguiram definir. Não que a Filosofia possua o monopólio do conhecimento, mas se percebeu a identidade de conteúdo e que podem servir de questionamento a ambas as áreas do conhecimento.

A fundo, o trabalho tem uma forte raiz hermeneuta, já que busca uma releitura analógica para com vários institutos como a principiologia do Processo Civil de 2015 e as figuras tão discutidas na filosofia: a da linguagem, socialização e interação humana.

Basicamente, propõe-se topograficamente a (a) tratar do CPC-2015 diante da alteração de sua base principiológica e epistemológica, bem como os clamores sociais ligados à esta mudança; (b) fazer uma correlação de tais questões para com os aspectos filosóficos acerca da linguagem, socialização e interação humana; e (c) demonstrar que, de fato, o Processo Civil de 2015 é um instrumento qualificador do processo de linguagem social, facilitando dessa forma o acesso à justiça.

Permeia-se a ideia do acesso à justiça dentro de uma perspectiva de justiça substancial, a partir de um diálogo concreto, dado por todos aqueles que de alguma forma estão ligados ao processo [partes ou não]. Figura-se que a instrumentalidade do processo é uma via concreta e possível de um diálogo maduro e qualificado pela linguagem interacional, sempre que estiver sobreposta pela justa compreensão do telos [fim/destino/interesse] social, dadas as expectativas sociais de seu respectivo momento histórico e evolutivo.

A necessidade do estudo parte de uma revisão sistemática do processo civil, de onde se percebeu uma grave carência doutrinária acerca de estudos que envolvam a correlação entre o Código de Processo Civil de 2015 para com os estudos filosóficos relacionados à linguagem, socialização e interação humana, sobretudo, relacionados a tema que envolvam questões processuais civis sob o âmbito dos níveis pré-convencional, convencional e pósconvencional.

Para dar fundamentação teórico-analógica, aderem-se às lições de Cândido Rangel Dinamarco, especialmente por sua obra "Nova era do Processo Civil", onde destaca a 
essencialidade dos princípios de processo e a forma como devem ser previamente interpretados [de forma harmônica, por exemplo].

A proposta também parte da concepção filosófica de Jürgen Habermas, o qual, por sua vez, alicerça-se nas memoráveis lições do psicólogo Lawrence Kohlberg acerca da moralidade. Basicamente, este último dividia seus estudos em seis estágios, posicionados em três níveis para justificar o processo evolutivo na capacidade do julgamento moral e na formação da consciência moral (BANNWART JUNIOR, 2017, p. 30-31), as quais são bem destacadas pela doutrina do filósofo-jurista Clodomiro José Bannwart Junior, em sua obra "Responsabilidade Integral. Metodologia Estratégica para o Desenvolvimento Pessoal, Corporativo e Educacional".

O presente trabalho se desenvolve, ainda, em observância às várias leituras de ordem complementares e gerais, a partir da percepção de que até mesmo nos estudos acerca das regras do discurso, tão importantes para a compreensão do presente tema, a doutrina filosófica é divergente e, assim, dificulta uma importante perspectiva do atual Código de Processo Civil [de 2015], ainda pouco explorada. Por exemplo, o embate entre as correntes dos alemães Jürgen Habermas e Robert Alexy (CARVALHO, 2013, p. 29-31).

Em linhas gerais, nos itens subsequentes, utilizando-se do método dedutivo, discorrese a partir da concepção de que o telos não deve estar previamente estabelecido pela norma jurídica, pelo processo instrumentalizado e por seus procedimentos, mas sim o conceber dentro de um horizonte de expectativas sociais, qualificando a moral para não mais um período simplesmente contratualista, mas sim vinculado também a princípios.

\section{O CPC-2015 E A ALTERAÇÃO DE SUA BASE PRINCIPIOLÓGICA E EPISTEMÓLÓGICA}

Em comparativo para com o CPC-1973, muito se pergunta se o Código de Processo Civil de 2015 teve alterada sua base principiológica e epistemológica, ou seja, os princípios que servem de norte para todos seus demais dispositivos e formas de interpretação, condução e decisão; e inclusive, a sua própria noção de conhecimento [episteme], sobre como o Código se reconhece e se fixa dentro do ordenamento jurídico.

Parece que sim.

Em análise aos treze primeiros dispositivos do revogado Código e os doze iniciais do atual, percebe-se a ênfase principiológica conferida pelo legislador. Em outros termos, 
destacou-se de forma salutar a pertinência dos princípios que passam a nortear este novo tempo processual.

Talvez o mais referido seja o art. $6^{\circ}$, que prevê que todos os sujeitos do processo devem cooperar entre si para que se obtenha, em tempo razoável, decisão de mérito justa e efetiva. A cooperação, portanto, passa a visivelmente romper com a retrógrada ideia ou percepção da lide em sede absoluta contraposição de partes.

É neste ponto, quanto à sua noção de conhecimento ou autoconhecimento [epistemologia], que o Código de 2015 ganhou alento: percebe-se que o Estado promoverá a solução de conflitos, sempre que possível, de forma consensual [art. $3^{\circ}, \S 2^{\circ}$; de que aquele que de qualquer forma participa do processo deve comportar-se de acordo com a boa-fé [art. $5^{\circ}$ ] e dar prioridade ao processo cooperativo [art. $6^{\circ}$ ].

Este alento deriva de que a boa-fé, a cooperação e a tutela jurisdicional não se encontram mais num "plano acessório ao processo", tal como se previa no art. 14, II do CPC73 [que o indicava de forma tão modesta e ocultada], mas agora incluído na parte introdutória e numa superfície topográfica de destaque e qualificada ao leitor e a todos os sujeitos à referida Lei. É como se o legislador dissesse [e, de certa forma, o diz]: qualifico o princípio para o fazer constar como base fundamental de toda da estrutura processual civil.

Os efeitos desta alteração serão mais a frente tratados, mas por ora se percebe o quanto o processo, em sua instrumentalidade, corrobora com o diálogo de seus legitimados. E na medida do tempo, o próprio processo é relido e remoldado, de modo a corresponder com as expectativas de interesses de seu respectivo tempo.

No remoto tempo em que vigoravam as Ordálias, por exemplo, os princípios norteadores eram manifestamente outros; no revogado Código de Processo Civil de 1973, ainda que aqueles indicados já o tivessem sido defasados ao tempo de sua publicação, também outros; agora, novamente, ao tempo do CPC-15, são novas as bases principiológicas. Ademais, esta questão parece incontroversa, sobretudo num tempo que a ciência e tecnologia, ao lado da religião, passam a fazer com que o homem rediscuta sua própria razão existencial. Portanto, quanto mais pela forma como intervém no corpo social, tal como pelo processo.

O problema das alterações das bases principiológicas não está no fato da simples e formal alteração [afinal, elas advém para a otimização do ordenamento], mas quando ela não corresponde materialmente mais ao tempo em que deveria se fixar. Seria o mesmo que tão logo da vigência do CPC-2015, já se começar a discutir se os princípios já estão ultrapassados 
ou não, se nem mesmo se entendesse ou compreendesse a razão intencional do legislador de 2015, para dar o próximo passo legislativo.

Talvez esteja exatamente aí a necessidade de se reler o Código Processual Civil a partir de seu conjunto de princípios: O Código que não compreende o conjunto principiológico de seu tempo, necessidades e interesses, bem como a sociedade que em contrapartida não compreende a Lei, caem em insegurança jurídica. Há a desestruturação da própria credibilidade do sistema processual.

Mais que isto: como já advertido por Cândido Rangel Dinamarco, os princípios e garantias atuam num sistema que deva oferecer um processo justo, mas muitas vezes para uma tutela jurisdicional efetiva, é preciso o sacrifício da "pureza de um princípio" para com outro, de modo a evitar a condução a rumos indesejáveis. Assim, a leitura de um princípio será feita na convivência harmônica de outro, já que "nenhum princípio é um objetivo em si mesmo e todos eles, em seu conjunto, devem valer como meios de melhor proporcionar um sistema processual justo" (DINAMARCO, 2011, p. 13-14).

Pensa-se que é exatamente neste ponto em que pecava o CPC-1973, exatamente porque não se amoldava a seu tempo e mantinha a estrutura formal de um processo menos dialógico e cooperativo, veja-se: mesmo prevendo expressamente os princípios da boa-fé [art. 14, inc. II], que é muito mais amplo [e, assim, engloba] o princípio da cooperação para um justo resultado.

Pelas consideráveis advertências de Cândido Rangel Dinamarco, aqui e de forma autônoma, passa-se também a pensar que o CPC-2015 pode pecar ao eventualmente fazer com que a sociedade se paute exclusivamente numa cooperação desenfreada, portanto, sem a análise de todo o sistema principiológico que se funda o CPC-2015. Como ele rubrica, “desfazer dogmas ou ler os princípios por um prisma evolutivo não significa renunciar as teses, ou repudiar as conquistas da ciência e da técnica do processo" (DINAMARCO, 2011, p. 14).

Desta forma, tem-se que é preciso que se identifiquem os efetivos problemas que afetam a ordem processual e que toda a sociedade compreenda a função fundamental do processo [dentro de uma adequada linguagem, noção de socialização e de interação humana], para este tempo. 


\section{ASPECTOS FILOSÓfiCOS ACERCA DA LINGUAGEM, SOCIALIZAÇÃO E INTERAÇÃO HUMANA}

Estabelecer-se no processo civil com boa fé, mediante cooperação e na busca de resultados justos e adequados, é uma tarefa desafiadora. Sendo assim uma tarefa, pode-se dizer que há necessidade de um prévio comportamento adequado da parte, cuja adequação está intimamente ligada ao que se entende por ética e moral e a forma como ela se mescla no corpo social.

Assim, e de forma equivalente, recorda-se das lições de Clodomiro José Bannwart Junior, em que o comportamento ético e moral é resultado de um processo de aprendizagem; o processo interacional implica, decididamente, a construção de valores éticos e princípios morais; e o processo ético resulta do crescimento individual e da maturidade (2017, p. 27). Portanto, é imprescindível que as partes disponham de um comportamento adequado e fruto de um constante processo de aprendizagem.

Talvez aí esteja a essencialidade da compreensão dos princípios gerais e informativos do processo civil à luz de um processo de aprendizagem e interacional das partes. Para se chegar a um processo ao mesmo tempo cooperativo, justo e adequado, é preciso o compreender dentro dos preceitos éticos e morais. O resultado disso é, além de tudo, o reconhecimento de uma postura de crescimento e maturidade humana.

Pensa-se que esta compreensão pode ser adquirida pelo conhecimento, o qual é adquirido a partir de nossa "capacidade de comparar, ponderar, mensurar, metrificar, pesar, etc. (BANNWART JUNIOR, 2017, p. 23)", afinal "há apenas duas circunstâncias que impedem a responsabilização do ato humano: a ignorância e a coerção”; $e$ "o amadurecimento ético e moral é decorrente do processo educacional" (BANNWART JUNIOR, 2017, p. 27-28).

Talvez aqui se compreenda que o processo civil compreende parte desse processo de gestão de relacionamento interpessoal. Mas o fato é que referida gestão deve ser vista não apenas do ponto de vista teórico, mas também pragmático. Em alusão, o aspecto teórico se coloca como "fundamento do interesse técnico na ordem do conhecimento que se pretende racional"; de outro norte, sob o aspecto prático, "revela-se no processo assegurado pela interação humana e visa a geração da compreensão mutua dos momentos integrantes de determinados contextos sociais" (BANNWART JUNIOR, 2017, p. 28). Entretanto: 
[...] âmbito interacional revela a necessidade do uso adequado e coerente da linguagem ordinária, ao assegurar a interpretação do sistema simbólico que prevalece no cotidiano, propiciando o acordo e o consenso sobre os valores praticados. A linguagem é ferramenta indispensável no processo de socialização, inclusive detendo conotações transcendentais, a saber, as condições de possibilidade do entendimento mutuo, do consenso e da própria legitimidade interacional. Habermas, por exemplo, relaciona a dimensão da interação à ação comunicativa, demonstrando que a linguagem é portadora de racionalidade comunicativa - capaz de legitimar os acordos firmados e os consensos pressupostos (BANNWART JUNIOR, 2017, p. 28).

Se a linguagem é ferramenta indispensável no processo de socialização, como a utilizar diante da falta de compreensão acerca da moralidade? Neste sentido, ao estudar este último instituto, Lawrence Kohlberg [psicólogo] o dividiu em seis estágios, posicionados em três níveis para justificar o processo evolutivo na capacidade do julgamento moral e na formação da consciência moral. Elas estão diretamente ligadas aos estágios de como se percebe a regra e a dimensão de independência do indivíduo em face da norma ou regra estabelecida. No primeiro nível, tem-se o pré-convencional, onde há o desconhecimento do agente [uma ingenuidade, um egoísmo; mas a obediência por medo de punição], de modo que tudo aceitará seja por fato natural, quanto por ordem de autoridade; no segundo, qual seja o nível convencional, há não apenas a compreensão, mas também o respeito à regra, e isto ocorre exatamente pela consciência da existência de uma cooperação social [idealidade do bom menino; e a busca de preservação da autoridade e da ordem social]; e, por fim, o nível pós-convencional, onde o agente já detém as condições para dividir o caráter consensual e convencional da norma, passando a se orientar por princípios abstratos e universais [compreende-se por um legalismo-contratual ou de utilidade e direitos individuais; ou por princípios universais] (BANNWART JUNIOR, 2017, p. 30-31);

Perceba-se que no nível convencional, que leva em consideração as expectativas interpessoais mútuas, sejam pelo quarto estágio, onde há orientação “da lei da ordem”, caracterizadas pela vida boa e justa, a eticidade se encontra presente. No terceiro, uma eticidade de interesses satisfatórios; no quarto, uma eticidade transposta pelo hábito de um sistema normativo. Aqui, em ambos os estágios, a sanção é a vergonha do agente, que se conduz de forma a evitá-la (BANNWART JUNIOR, 2017, p. 34).

Referida eticidade não é mais encontrada no plano pós-convencional, já que esta se alicerça em princípios morais. O legalismo contratual e os princípios universais correspondem, respectivamente, à liberdade civil e a beneficência pública e à liberdade moral. 
Portanto, aqui a justificação passa a ser única e exclusivamente de pontos de vistas universalistas. Diga-se: de pressupostos linguísticos garantidores da formação consensual da vontade e da opinião (BANNWART JUNIOR, 2017, p. 34-35).

Portanto, no período pré-convencional o que importa é o resultado privado; no convencional, limita-se ao reconhecimento da alteridade, ou seja, as ações são praticadas por um agente em consideração a expectativa depositada por outro; e no pós-convencional, não há imposição de um telos [exigindo do agente apenas um compromisso ético e moral somente a partir da habilidade no emprego de meios], mas sim a valorização dos princípios que respeitam aos direitos e garantias fundamentais. Observa-se que neste último estágio, os fins são construídos no horizonte da expectativa social. Com isto, há preservação de uma formação consensual da vontade e opinião, sob apenas uma coerção, qual seja, do melhor argumento (BANNWART JUNIOR, 2017, p. 38-39).

Nessa linha, pergunta-se: em qual nível se encontra o processo civil? Ou melhor, em qual nível as partes que compõe o processo jurisdicional estão? Quais são suas percepções acerca da linguagem, interação humana, socialização, eticidade e moralidade? Dentro do processo, onde se encontra e como é disposto socialmente o telos? E principalmente: conforme o ordenamento jurídico brasileiro e a forma como se dispõe a sociedade, quais são as condições de possibilidade da linguagem? E quais são os princípios universais que norteiam o processo civil de 2015 ?

Estas questões estão há anos tentando ser respondidas e seria temerário aqui se posicionar de forma definitiva. Entretanto, pensa-se que é correto reconhecer que para o acolhimento social de tais concepções teóricas é preciso admitir que o homem caminha num processo evolucional [teoria da mudança estrutural] - que está intimamente ligada ao plano pragmático - e o deverá fazer dentro dos padrões formais de estruturas de racionalidade. Jürgen Habermas, a partir da teoria da aprendizagem, acolhe as lições de Lawrence Kohlberg e as quer ampliar ao plano social (BANNWART JUNIOR, 2017, p. 48). Assim, pensa-se para se tratar dos objetos deste trabalho que é preciso compreender a necessidade de que a sociedade incorpore concretamente a importância da linguagem, socialização e interação humana.

\section{O PROCESSO CIVIL DE 2015 COMO INSTRUMENTO QUALIFICADOR DO PROCESSO DE LINGUAGEM SOCIAL}


Numa releitura dos tópicos anteriores, parece íntima a relação entre os reclamos do processo civil de 2015, que conclama um novo tempo principiológico e epistemológico, para com os aspectos filosóficos acerca da linguagem, socialização e interação humana. A boa-fé, a cooperação [em especial] e uma tutela justa e adequada passam a pairar no plano interativo das partes e daqueles que de alguma forma intervém no processo.

Muito se fala em exigência de uma eticidade das partes do processo, com um foco cooperativo e o rechaçar de condutas meramente litigantes e de contraposição, por meio dos artifícios positivos e de legalidade formal. Mas, afinal, a eticidade do ponto de vista filosófico [ao menos sob as lições de Lawrence Kohlberg e Jürgen Habermas] não estaria ligada a um nível convencional, portanto, já manifestamente defasado?

Como já tratado, pelo processo educacional, esperar de cada parte e exigir dela uma subjetividade apropriada é arriscada, pois aqui ingressaríamos na discussão agostiniana se o homem é bom ou não, o que poderia prejudicar todo o discurso. É preciso, assim, compreender que a postura das partes no processo judicial civil passa por uma ordem de gestão de relacionamento interpessoal, de modo que é preciso previamente considerar a construção do conhecimento não apenas de um ponto de vista teórico, mas também pragmático.

Se o homem e o processo caminham num nível pós-convencional, como já dito, não é possível agora definir. No entanto, é certo que nesse nível há a compreensão de que a eticidade está enlaçada por um telos "definido" pela norma, de forma a fazer com que as partes ajam apenas para cumprimento de meios adequados, o que não resolve os problemas. Os anos de luta do Poder Judiciário, inclusive com políticas de desmassificação de processos, ou até mesmo na escolarização acerca dos meios alternativos de solução de conflitos, são exemplos disso.

Assim, entende-se que, de fato, é preciso que não haja a definição prévia de fins juridicamente estabelecidos, de modo que estes sejam construídos no horizonte da expectativa social, pois a sociedade é complexa e evidentemente carece da definição de padrões universais, sobretudo de princípios universais [os quais estão mais próximos do que se entende por moralidade]. Deste modo, parece mais adequado dizer de um processo civil moralizado e moralizador, do que simplesmente ético.

Com base no tema proposto, talvez seja exatamente nos princípios o ponto de intersecção entre o Direito, sob a ótica do processo civil, e a Filosofia. De um lado, parte dos 
processualistas, o Estado e considerável parte da sociedade reclamam que o processo seja um lugar de diálogo não apenas das partes, mas de toda a sociedade, exatamente pelos efeitos direitos e indiretos que o processo jurisdicional infere para além das partes. Para isto, dizem que é preciso mudar os princípios. De outro, da Filosofia, que reclama conjuntamente [dentre outros] o estudo de questões gerais relacionadas ao existencialismo humano, seus valores e forma de linguagem. E, como visto, também refletir sobre a doutrina que milita pelo reconhecimento de princípios universais.

Pensa-se que não há dissonância entre as áreas do conhecimento, afinal, até mesmo os referidos estudos acerca da moralidade - tomados por Habermas - advém de profissional da psicologia, que é o caso de Lawrence Kohlberg. Assim, uma coerência principiológica universal é que possibilitará a compreensão universal para o processo jurisdicional civil.

E como fazer isto? Dizer apenas que é preciso um processo educacional por depender da subjetividade de cada indivíduo [parte] é muito vago, afinal se poderia até mesmo voltar aos tempos de discussões de Karl Marx e Friedrich Engels. A educação é importante, mas sobre esse ponto está a necessidade de se reconhecer a essencialidade na formação consensual da vontade e opinião, a partir de programa pragmático, pautado num processo evolucional [teoria de mudança estrutural] e de aprendizagem. Pensa-se que aqui há proximidade com um programa de racionalidade e universalidade. Todavia, o quesito é como isso se dará?

Acredita-se que é exatamente na linguagem, na socialização e na interação humana que os primeiros passos serão conferidos com maior presteza. Veja-se: não se limita a estes elementos, pois o telos é construído conforme os clamores sociais [suas expectativas] de seus respectivos tempos - e não de modo previamente posto, como uma regra ou uma eticidade mal compreendida.

Um parêntese: Note-se que eticidade não é excluída por completo, mas a eticidade não passa a previamente determinar um fim [noção de nível de convencionalidade], até porque o Código de Processo Civil de 2015 possui uma dimensão ética, quando rubrica a necessidade de (a) publicidade, (b) segurança jurídica, (c) sistema adequado, (d) uma jurisprudência isonômica e, especialmente (e) de confiança.

Deste modo, as dimensões pragmáticas que reclamam o CPC-2015, tais como seu caráter pragmático, de eficiência, funcionalidade, de solução e simplificação procedimental, somam-se à moralidade [sua dimensão moral] que preconiza uma justa decisão. Esta moralidade é correspondida pelos princípios universais que a formam e, assim, permite-se um 
maduro diálogo entre as partes do processo, que pode ser mais bem classificada como uma reciprocidade a partir de regras de discurso.

Mas como dialogar e criar uma linguagem que seja compreendida por todas as partes [e que assim permitam a construção evolutiva do homem, pelo processo jurisdicional]? Pensase que as técnicas - as regras do discurso [com participação equitativa e universal à argumentação] - poderão responder, eis que buscam não apenas a fala, mas a perspectiva do mundo conforme o mundo objetivo, social e subjetivo (PINTO, 1995, p. 1-11).

Neste sentido, importante destacar que o discurso não deve aproximar os princípios dos valores, tal como explica Habermas:

[...] Habermas critica, ainda, a aproximação alexyana entre princípios e valores, ao fundamento de que, mediante tal aproximação, os princípios perderiam a característica de código binário para se transformarem em um código gradual. Deixa-se de falar em adequabilidade, e passa-se a falar em preferibilidade, de modo que os princípios não mais indicam o que é devido, mas o que é preferível, e correse o risco de se confundir direitos com bens que podem ter sua aplicação negociada conforme as preferências da autoridade que decide (CARVALHO, 2013, p. 30).

Talvez o discurso enfrente problema exatamente por questões tratadas pelas preleções habermasianas: Como se falar em uma base universal da fala [transcendental], diante da complexidade social e da complexidade entre o pragmatismo relacionado às pretensões de validade, relacionadas à verdade, correção e veracidade [do mundo objetivo, social e subjetivo] (PINTO, 1995, p. 3) daqueles que dialogam? A resposta talvez possa ser tema de outro trabalho, mas o foco aqui buscado é exatamente de se verificar a importância do processo jurisdicional civil como um canal de diálogo de partes [noção de linguagem, socialização e interação humana].

Note-se a complexidade do tema, pois o processo judicial é um instrumental à tutela jurisdicional e está presente com as partes, a figura do julgador e daqueles outros que participam, de algum modo, para a realização da prestação jurisdicional. Sem qualquer crítica, não basta os princípios universais serem pragmaticamente compreendidos pelas partes, mas por todos que do processo participam. Faz-se estas considerações porque por mais que não coadunem com todos os seus posicionamentos, é importante o questionamento de Ronald Dworkin, que assim o fez como título de capítulo de livro: "Não existe mesmo nenhuma resposta certa para casos controversos?” (DWORKIN, 2005, p. 175). Apenas o 
questionamento nos conduz a refletir ainda mais sobre a importância do processo, afinal, a controvérsia [noção de lide] demanda uma resposta certa?

Verifica-se, assim, a importância do Código de Processo Civil de 2015 como um qualificador da linguagem, socialização e interação humana. É um espaço de diálogo que também é qualificado pela prestação jurisdicional que se reclama justa. Destarte, pela leitura da base principiológica trazida pelo Código de Processo Civil de 2015, percebe-se tais identidades teóricas e pragmáticas dadas pelo Direito e pela Filosofia. Essa visão permite cogitar de se alçar o objetivo do acesso à justiça a outro patamar evolutivo.

Note-se que se o diálogo deve compreender não apenas as partes do processo, mas todos aqueles que direta ou indiretamente sofrem reflexos e, sobretudo, nele interferem, como é o caso dos julgadores. Retoma-se a própria base de conhecimento acerca do acesso à justiça. Isto porque este [o acesso à justiça], como garantia fundamental e tão importante no atual estágio do Estado Democrático de Direito, passa pelo crivo de uma ordem justa [formal e material/substantiva], a qual, por sua vez, está alicerçada numa composição sistemática e mínima de observância daqueles [todos os agentes] que dialogam. Neste sentido, recorda-se das lições de Kazuo Watanabe, que descreve que a ordem justa pressupõe uma justiça composta por julgadores capacitados, comprometidos e "sensíveis aos problemas sociais" (WATANABE, 1988, p. 135). Ou seja, juízes que compreendam que o acesso à justiça substantivo é permeado dentro de um diálogo interacional, bem como de que este diálogo ainda não é concreto, ou seja, ainda consubstancia um "problema social". Deste modo, a importância do diálogo através do processo garante, por seus diversos vieses, o acesso à justiça.

Portanto, se o telos social deve estar em consonância com o respectivo e adequado modelo social de seu tempo, ou seja, estar numa constante construção, o acesso à justiça como o acesso a uma ordem justa - conforma a essencialidade da instrumentalidade do processo e a necessidade de um adequado diálogo. Como ensina Cândido Rangel Dinamarco, a ideia de efetividade da tutela jurisdicional, coincide com a plenitude do acesso à justiça e a do processo civil “de resultados” (DINAMARCO, 2002, p. 156). De tal modo, há um plexo de combinações fundamentais: um processo civil instrumental e adequado para a concretude de uma prestação jurisdicional; de uma compreensão do acesso à justiça sob sua ótica substancial; e que aquela instrumentalidade e esta substancialidade sejam vista através da releitura do diálogo, ou seja, de uma linguagem qualificadora e interacional humana. 


\section{CONCLUSÃO}

Antes das efetivas conclusões, constatou-se que tantos as doutrinas do Direito, quanto da Filosofia tratam e se fundam em princípios ou, dada a melhor expressão, em uma ordem principiológica, cada qual com sua respectiva definição. Percebeu-se que em que pese tratarem de "princípios", analisam estes a partir de fontes diversas. No entanto, as bases que justificam tais princípios são equivalentes, ou seja, há um manifesto grau de complementaridade e convivência entre as bases principiológicas de cada campo do conhecimento. Por esta razão, concluiu-se pela pertinência e coerência do tema em relação às duas disciplinas.

Um dos objetivos da presente revisão foi o de verificar a possibilidade de estudos hermenêuticos acerca do tema. Foi possível constatar não apenas que sim [acerca da possibilidade], mas a essencialidade e urgência do tema, com vistas ao saneamento dos reclamos sociais, a partir de uma teoria aplicada.

Como se denotou, o presente estudo foi metodologicamente pautado pelo objetivo exploratório. Utilizou-se do método dedutivo para, através do levantamento de dados via pesquisa bibliográfica, especialmente em periódicos e doutrinas atinentes aos campos do Direito Processual Civil e da Filosofia, trazer consigo uma visão analógica e axiológica acerca do tema. Assim, propõe-se uma [re]análise analógica dos princípios norteadores do Código de Processo Civil de 2015 a partir as compreensões filosóficas acerca da linguagem, socialização e interação humana, bem como como estes campos se relacionam e se dispõe no contexto social.

Exatamente nessa linha, conclui-se que o processo jurisdicional, pautado pelo Código de Processo Civil de 2015, pode ser um qualificador da linguagem, socialização e interação humana, não servindo apenas de base instrumental para a conferência de uma tutela jurisdicional pura e simples, mas sim no ambiente comunicativo e de construção social. Isto parece evidente quando o Código permeia basicamente sob três dimensões, a pragmática, ética e moral.

O Princípios da cooperação e da boa-fé tão discutidos, quando relidos a partir das matrizes doutrinárias de Lawrence Kohlberg e Jürgen Habermas, parecem coadunar com a ideia de transcedentalidade do processo, ou seja, para interpretação do instrumento processual 
como qualificador da exigência de um processo de aprendizagem comunicativa e, sobretudo, evolutivo.

Hoje dizer que é preciso ser essencialmente ético nas condutas processuais parece [ao menos parece] estar equivocado, afinal, a moral [sob sua visão madura] é a que mais se aproxima da decisão justa, eis que se pauta nos princípios de universalidade. Mas veja-se que ainda não se está dizendo que o Processo Civil de 2015 esteja num nível pós-convencional, até mesmo porque evidente a existência de uma sociedade complexa [plural, de vários ângulos] e o processo de comunicação demanda efetivamente de um diálogo, onde os agentes [as partes] consigam compreender todos os sinais do processo comunicativo. Mas pode-se argumentar que seus dispositivos permitem vislumbrar esse âmbito pós-convencional.

O que se reflete aqui é: Os princípios universais tratados pelas lições habermasianas constituem o resumo dos princípios que buscam a tutela jurisdicional justa, quando conferidos de forma harmônica? Sem respostas conclusivas ou definitivas, por ora. Entretanto, pensa-se que este questionamento é importante ao se recordar das advertências de Cândido Rangel Dinamarco, quando diz sobre não se focar na pureza de apenas um princípio, mas todo o conjunto principiológico que, este sim, é uma matriz para se evitar rumos indesejáveis.

Como já destacado anteriormente, pensa-se que é preciso que não haja a definição prévia de fins juridicamente estabelecidos, de modo que estes sejam construídos no horizonte da expectativa social, pois a sociedade é complexa e evidentemente carece da definição de padrões universais, especialmente de princípios universais [os quais estão mais próximos do que se entende por moralidade]. Parece, portanto, mais adequado dizer de um processo civil moralizado e moralizador, do que simplesmente ético.

Acredita-se que a ética, em sua essência, será compreendida quando a sociedade, a filosofia e o Direito compreenderem, através do processo civil, a grandeza dos valores pessoais e sua transcendência para o plano social. Afinal, talvez este seja um dos maiores desejos da humanidade: o de conseguir, através de seus instrumentos legais, dialogar madura e socialmente de acordo com uma identidade de valores e em respeito às individualidades.

Por esta razão, verifica-se que o Código de Processo Civil de 2015 não deve estar apenas posicionado de forma estática, indicando apenas um telos previamente estabelecido na norma, a fim de não retroceder nos níveis de moralidade [convencional ou pré-convencional], mas sim conceber uma transcendência racional da norma, do instrumento processual e de seus procedimentos a partir linguagem, socialização e interação humana. 
Assim, compreende-se que o telos é construído ao longo do tempo, conforme as expectativas sociais, pois do contrário pode-se criar uma grave frustração social e, assim, a ineficácia das normas processuais. Ou seja, que haja ineficiência do processo civil em razão das dissonâncias sociais.

É notável, desta forma, a concepção de que o processo civil e sua aplicação passam necessariamente pelo crivo da linguagem, socialização e interação humana, ainda que de forma intrínseca. É impossível dissociar os planos próprios das ciências humanas para com as das sociais aplicadas, tal como, respectivamente, propõem a Filosofia e o Direito.

Ainda que não seja possível, ao menos por ora, encontrar uma definição acerca do tema, tais como quais caminhos urgentemente tomar, de discernir quais os vieses mais adequados e que possam conformar tal litígio teórico-prático, de descrever quais os instrumentos e formas de aplicação em nível social, tem-se que é possível que a ciência compreenda quais são as fontes universais humanas. São elas diretrizes que independentemente do caminho, tempo e forma como a Filosofia e o Direito convivem, buscam construir o melhor método de interpretação. Em outros termos, ainda que estes campos do conhecimento demorem em reconhecer sua convergência, o Código de processo civil de 2015 deve ser interpretado a partir das matrizes universais humanas, cada parte compreendendo seu grau de intervenção social através do processo e a essencialidade deste como instrumento vivo de pacificação social.

O processo, como discorrido, é um espaço de diálogo que também é qualificado pela prestação jurisdicional que se reclama justa, especialmente pelo tempo em que se contempla aplicação, o do CPC-2015. Pela simples leitura de suas bases principiológica, trazidas nos dispositivos inaugurais, percebe-se tais identidades teóricas e pragmáticas dadas pelo Direito e pela Filosofia.

Note-se que a sociedade que existe ainda buscando uma simples convencionalidade, pode, por um justo e maduro diálogo, encontrar as dimensões éticas, rubricadas, dentre outros, pela segurança jurídica, produzindo um sistema adequado, uma jurisprudência isonômica e, especialmente, de confiança [seja entre as partes, seja com o Estado].

Deste modo, e como dito, as partes no processo judicial civil precisam se envolver em uma ordem de gestão de relacionamento interpessoal, por uma prévia construção do conhecimento [excluindo a ignorância e a coerção] não apenas de um ponto de vista teórico, mas também pragmático. O Código de Processo Civil de 2015, visto a partir de uma raiz 
hermenêutica, pode conduzir a uma positiva construção entre teoria e prática, garantindo a eficácia e eficiência das normas processuais e, notadamente, a construção de uma sociedade mais justa e pacificada, permitindo melhores perspectivas de acesso à justiça. Assim, se a teoria é um primeiro passo, o presente trabalho se propõe a também de forma positiva idealizar a criação de um espaço de diálogo não apenas entre juristas, mas também em atenção a todas as esferas de conhecimento, como é o caso das ciências humanas.

Talvez assim se compreenda melhor a definição de Cândido Rangel Dinamarco para a "Teoria Geral do Processo", quando a afirma como "um sistema de conceitos e princípios elevados ao grau máximo de generalização útil e condensados a partir do contorno dos direitos ramos do direito processual" (DINAMARCO, 1994, p. 59). A própria teoria geral se funda numa articulação sistemática de informações e cria um sistema [ou seja, um conjunto de elementos] que permite a compreensão do processo civil de acordo com a máxima elevação principiológica, sem prejuízo de sua identidade [processual; do Direito]. Em outras palavras, o processo civil está aberto para articular com as demais ciências voltadas ao conhecimento humano e social.

Com esta concepção de processo, como espaço aberto agora para as próprias ciências, o acesso à justiça, que por si só justifica um alicerce de um Estado Democrático de Direito, ganha novos contornos interpretativos e que conduzem a uma melhor aplicação prática do Direito. Mas note-se, não apenas do Direito, mas de todas aquelas que se conduzem sob o mesmo telos [como o caso da Filosofia, a que se permitiu ênfase fundamentadora] e com as mesmas propostas evolutivas. Não há como se negar a pertinência da combinação do processo, da linguagem e interação humana para com o acesso à justiça.

Portanto, de modo particular, é imperioso aferir o considerável grau de interferência do diálogo [como mecanismo interacional] nas noções fundamentais da garantia constitucional do acesso à justiça. O processo, em sua instrumentalidade e sendo um espaço de diálogo, faz-se supedâneo entre aqueles meios socialmente criados para a garantia de uma ordem justa e que, na medida do tempo, reprima as deficiências sociais, dentre elas a do mau emprego da própria linguagem interacional e socializadora. É a partir do sanar destas deficiências que se poderá melhor responder se estamos em um período realmente pósconvencional, como ao menos se aparenta.

Por fim, tem-se que é preciso que o acesso à justiça seja examinado dentro de um plexo dinâmico de combinações, que assim considerem: o processo civil como um 
instrumental adequado para a concretude de uma prestação jurisdicional; de uma compreensão do acesso à justiça sob sua ótica substancial; e, de forma especial, que a instrumentalidade e substancialidade precedam da releitura do diálogo, ou seja, de uma linguagem qualificadora e interacional humana, tal como propõem os estudos sistemáticos das ciências humana e sociais aplicadas. O Código de Processo Civil de 2015, nesse passo, em sua principiologia e epistemologia, garante este espaço interacional, especialmente pela previsão de aplicação do princípio da boa-fé e o da cooperação processual. Não apenas isso, por sua proposta, conclama a garantia constitucional do acesso à justiça, mas sua efetiva aplicação dependerá de como as partes e demais interessados interpretem o Código de processo civil de 2015 e o acesso à justiça a partir da linguagem, socialização e interação humana.

\section{REFERÊNCIAS}

BANNWART JUNIOR, Clodomiro José; CATARINO, Dilson; LIMA, Gleiton; NUNES, Liliane. Responsabilidade Integral. Metodologia Estratégica para o Desenvolvimento Pessoal, Corporativo e Educacional. Londrina: Midiograf, 2017.

CARVALHO, Juliana Brina Corrêa Lima de. Sobre os Limites da Argumentação Judicial: Ativismo Judicial, Jürgen Habermas e Chantal Mouffe. Revista do Direito Público, Londrina, v.8, n.1, p. 9-52, jan./abr.2013.

DINAMARCO, Cândido Rangel. Nova era do Processo Civil. 1. ed. 2. Tiragem. São Paulo: Malheiros, 2004.

Fundamentos do processo civil moderno. 1. ed. São Paulo: Malheiros, 2002

A instrumentalidade do processo. 4. ed. São Paulo: Malheiros, 1994.

DWORKIN, Ronald. Uma questão de princípio. 2. ed. Tradução Luis Carlos Borges. São Paulo: Martins Fontes, 2005.

PINTO, José Marcelino de Rezende. A teoria da ação comunicativa de Jürgen Habermas: conceitos básicos e possibilidades de aplicação à administração escolar. Paidéia (Ribeirão Preto). n. 8-9 .Ribeirão Preto Feb./Aug. 1995. Disponível em: <http://dx.doi.org/10.1590/S0103-863X1995000100007> Acesso em: 5 jul. 2019. WATANABE, Kazuo. Acesso à justiça e sociedade moderna. In: GRINOVER, Ada Pellegrini (Org.). Participação e processo. São Paulo: Revista dos Tribunais, 1998. 
